\title{
The Reflective Learning Continuum: Reflecting on Reflection
}

\author{
James W. Peltier \\ Arno Kleimenhagen Professor \\ University of Wisconsin-Whitewater \\ College of Business \& Economics \\ Whitewater, WI 53190 \\ Voice: 262-472-5474 \\ Fax: 262-472-4863 \\ peltierj@uww.edu \\ Amanda Hay \\ Nottingham-Trent University \\ Nottingham Business School \\ Nottingham NG1 4BU \\ Voice: 0115-848-4364 \\ Fax: +44(0)-115-948-6512 \\ amanda.hay@ntu.ac.uk \\ William Drago \\ University of Wisconsin-Whitewater \\ College of Business \& Economics \\ Whitewater, WI 53190 \\ Voice: 262-472-3994 \\ Fax: 262-472-4863 \\ dragow@uww.edu
}




\section{The Reflective Learning Continuum: Reflecting on Reflection}

The importance of reflection to marketing educators is increasingly recognized. However, there is a lack of empirical research which considers reflection within the context of both the marketing and general business education literature. This paper describes the use of an instrument which can be used to measure four identified levels of a reflection hierarchy: habitual action, understanding, reflection and intensive reflection and two conditions for reflection: instructor to student interaction and student to student interaction. Further we demonstrate the importance of reflective learning in predicting graduates' perception of program quality. Although the focus was on assessment of MBA level curricula, the findings have great importance to marketing education and educators. 


\section{THE REFLECTIVE LEARNING CONTINUUM: REFLECTING ON REFLECTION}

Porter and McKibbin's 1988 now infamous report entitled "Management education and development: Drift or thrust in the $21^{\text {st }}$ century" was an ominous warning to administrators and educators alike. Though many deficiencies were highlighted in that report, of particular relevance to marketing educators was the perceived inability of students to identify business problems across a wide range of integrated decision environments, to understand and appreciate the entire gamut of decision-oriented processes and experiences, and to comprehend and prepare for a lifetime of learning. While nearly two decades have past since the timeframe of that study was initiated, these same sentiments are being echoed about today's MBA programs (Richards-Wilson, 2002; Stevens, 2000). Pfeffer and Fong (2002) contend that there is an over emphasis on analysis at the expense of decision integration and developing wisdom. Similarly, Mintzberg and Gosling (2002) criticize MBA programs for placing too much emphasis on the function of business rather than on the practice of managing business across a wide spectrum of personal experiences and decision dilemmas. The net result is that students entering the business world often lack the reflective thinking skills necessary for discovering insights through experience, necessary requisites to becoming life-long learners (Bourner, 2003; Braun, 2004).

In response to these concerns, pedagogy researchers are advocating curricular and educational practices that motivate, develop, and nurture reflective thinking in students (Hay et al., 2004a; Kember and Leung, 2005; Pfeffer \& Fong, 2002; Van Velzen, 2004). Although relatively scant discussions are found in the marketing literature (cf. Catterall et al., 2002; Graeff, 1997), reflection as a learning tool and action process has long been seen as a crucial prerequisite to effective decision making, especially in decision environments that contain ambiguous problems, unique elements, and no defined solutions (Pee et al., 2000; Schon 1983, 1987). Boud et al. (1996) portray reflection as cognitive and/or affective responses 
resulting from personal experiences that revise or create new understandings. Maclellan (2004) notes that this intention to revise extant understanding or to construct new meaning as experience unfolds incorporates a variety of mental and emotional processes, including dealing with fuzzy ideas to reconcile ambiguity and inconsistency; to recognize that one's current knowledge set may be confused, incomplete or misconceived; culminating in the purposeful realignment of meaning to that which is disparate. Mintzberg and Gosling (2004) argue persuasively that reflecting does not mean musing; reflection "means wondering, probing, analyzing, synthesizing - and struggling” (p 21).

Despite the lack of theoretical development and empirical investigations in the marketing and business education literature, a greater understanding and utilization of reflection has important ramifications for both the academic and business community. Arguably, one of the most important objectives of graduate business education is to develop leadership and leaders (Friga et al., 2003). Graduates who clearly understand that learning is a process of selfdiscovery, who challenge their own personal assumptions and beliefs, who question the actions that they and others take, and have a comprehensive view of effective managerial practices are well on their way to becoming effective leaders (Kayes, 2002). As Kouzes and Posner (2002) so aptly elaborate, effective leaders are constantly learning and see all experiences as learning experiences. In turn, leaders steeped in the tradition of reflection can move constituents to heightened degrees of consciousness and self-actualization (Bennis \& Nanus, 1997).

Adding to the general lack of reflection research in the marketing education literature is the paucity of instruments designed to operationalize and test this construct (Kember et al., 1999, 2000, 2004; Leung \& Kember, 2003). Importantly, the vast majority of research on reflection within and external to business education has been at the conceptual, rather than empirical level. Part of this dearth is due to the fact that there is no one consistent theory on 
reflection (van Woerkom, 2004). Moreover, nearly all of the empirical studies of reflection have either been qualitative in nature (c.f., Cope, 2003; Dempsey et al., 2001; Loo, 2002; Maclellan, 2004) or utilized instruments with relatively low reliability scores and/or that lacked sufficient validation (c.f., Kember et al., 2000, 2004; Leung and Kember, 2003). Of significance, The Association to Advance Collegiate Schools of Business, the primary accrediting organization for business programs, is requiring increased outcome measurements and assurance of learning reporting (AACSB International, 2004). To meet these assurance of learning standards, particularly as they relate to the role of reflective learning in the management curriculum, research is needed that develops the nature and scope of the reflection construct and that offers reliable and valid assessment tools.

Although the reflection construct has received relatively little attention in the marketing education and general business literature (Catterall et al., 2002), research on measuring student perceptions of their educational experience is pervasive. Although too extensive to review here, a wealth of recent marketing education literature relevant to our area of investigation suggest that marketing educators and learning environments are perceived to be most effective when students are proactive and engaged; when instructors and students actively engage and co-produce what is learned; when course content is competent, challenging, experiential and has real world relevancy; student-to-student interactions enhance the learning experience (for recent reviews, see Faranda and Clarke, 2004; Paswan and Young, 2002; Peltier et al., 2003; Smart et al., 2003; Smith and Van Doren, 2004; Wilhelm, 2004; Young, 2005; Young et al., 2003).

The intent of this paper is to address the limited attention given to reflection within the marketing education literature by bringing together research from multiple disciplines for the purpose of describing and developing the theoretical underpinnings of the reflective learning process, and importantly, to utilize an instrument that measures reflective learning. As part 
of this endeavour, we seek to identify the dimensions of reflective learning that impact how graduate degree recipients value the educational experiences that they received and how this education has benefited them upon entering the workforce. In this way, our research is consistent with calls by marketing educators to assess the value of the learning experience and how well these experiences carry-over to students' life-long learning process once in the workforce (Duke, 2002). Of importance, we provide evidence for the reliability and validity of an instrument for measuring the dimensionality of reflective learning and its impact on outcome assessment. It is important to note that because the extant literature in reflective thinking in marketing education is underdeveloped, we are directing our theoretical focus at the business curriculum and not specifically for marketing faculty and courses.

\section{REVIEW OF REFLECTION LITERATURE AND MODEL DEVELOPMENT}

Within the marketing education literature conceptual and empirical research on reflection is in its infancy. However, the reflection construct is receiving considerable attention in a wide range of disciplines including social work (Dempsey et al., 2001; Fisher and Somerton, 2000), information systems (Mukherjee, 2004), earth sciences (Harrison et al., 2003), leadership development (Densten \& Gray, 2001) and particularly in the areas of human resource development (Bourner, 2003; Corley \& Eades, 2004; Maclellan, 2004; Van Woerkom, 2004; Van Woerkom et al., 2002) and health sciences (Biggs et al., 2001; Kember et al., 2000; Leung \& Kember, 2003; Liimatainen et al., 2001). We examine this diverse literature base and blend it with emerging business education literature for the purpose of defining the reflection construct, identifying its dimensions and processes, and as input for further consideration of its measurement. 


\section{Reflection Defined}

Dewey (1933), one of the earliest pioneers in the field defined reflection as "active, persistent and careful consideration of any belief or supposed form of knowledge in the light of the grounds that support it and the further conclusion to which it tends" (p. 9). Dewey's view of reflective learning encompassed two interrelated ideas: "(1) a state of doubt, hesitation, perplexity, mental difficulty, in which thinking originates, and (2) an act of searching, hunting, inquiring, to find material that will resolve the doubt, settle and dispose of the perplexity" (p. 12). Building on Dewey, Kolb's (1984) experiential loop concept expressed reflection as one of four key processes through which individuals make sense of their experiences and in turn yields a basis for future action and initiates new or adapted ideas in the process. Similarly, Schon (1983) links reflection and experience through his concept of reflection-in-action as “....on the spot surfacing, criticizing, restructuring and testing of intuitive understandings of experienced phenomena..." (pp. 241-242). Focusing on reflection as a mechanism for change, Boyd and Fales (1983) defined reflective learning as "the process of internally examining and exploring an issue of concern triggered by an experience, which creates and clarifies meaning in terms of self and which results in a changed conceptual perspective" (p. 100). More recently, reflection and reflective learning have been defined in terms of adaptive learning (van Woerkom, 2004), self-construction (Dempsey, et al., 2001), self-awareness (Loo, 2002), coordinated understanding (Maclellan, 2004), and critical selfreflection (Cope, 2003). From these definitions it is clear that an important outcome of this exploration and internal examination process is changing one's perspective as new information and experiences are encountered (Hay et al., 2004a). As we note later, there is also a difference between general reflection and critical reflection. 


\section{The Reflection Process and the Non-Reflection $\leftrightarrow$ Reflection Hierarchy}

Boud et al. (1985) noted that reflection is an integrated learning process with multiple, though non-linear dimensions. They underscored the importance of experience and viewed the reflection process as having three interrelated stages: return to experience, analysis, and re-evaluation in terms of the emotional experiences and resulting re-integration of the outcomes that add to the learner's identity. Correspondingly, and based in part on the work of Dewey (1933), Mezirow (1981), Kolb (1984), Kember et al. (1999, 2000), Hay et al. (2004a), and others, the reflection process can be conceptualized in terms of awareness critical analysis - and change. Awareness, which is initiated when an individual becomes conscious of a previous experience, is often stimulated by positive or negative feelings about a learning situation. If salient, the event triggers the reflection process. In the second stage the individual performs a critical analysis of the experience, which involves identifying existing and pertinent knowledge, challenging internal and external assumptions, and seeking possible resolution alternatives. In the final stage, and if cognitive and/or emotional change is necessary, the individual reaches a new perspective, sometimes called perspective transformation (Mezirow, 1991). As a result of this reflection-based change, the individual alters firmly held beliefs, and ultimately, behaviour.

The majority of research on reflection has focused on its process orientation. More recently, and based on the initial work of Mezirow (1977, 1981, 1991), empirical research is emerging that investigates reflection in terms of hierarchical levels of learning (Cope, 2003; Hay et al. 2004a; Kember et al., 2000, 2004; Leung and Kember, 2003; Liimatainen, 2001; Maclellan, 2004; van Woerkom, 2002). Learning hierarchies are distinguishable in terms of the amount of effort needed for more basic, routine learning activities, compared to deeper cognitive processing necessary for generating new understandings and modifying internal theories for action (Argyris and Schon, 1996). Mezirow (1991) posited two broad hierarchies 
of learning actions: reflective (i.e., higher level learning) and non-reflective (i.e., lower level learning). Reflective learning is therefore seen as being associated with what has generally been described as higher level learning. Higher level learning is seen to encompass various forms of more intensive learning within the literature such as double loop learning, transformational learning and deep learning (Argyris, 2002; Cope, 2003). Moreover, Leung and Kember (2003) provide evidence for a relationship between a deep approach to learning and reflection and encourage the two interpretive frameworks to be used in concert.

Research by van Woerkom et al. (2002) supports the notion that higher level learning (reflection) is in part a function of self-efficacy, or the confidence managers have in their ability and courage to withstand social pressure, to be critical, to take a vulnerable position, to ask for feedback, and to evaluate their own performance. Likewise, building on Dewey (1933), Densten and Gray (2001) contend that the depth of learning is a function of openmindedness (i.e., listen to multiple perspectives), responsibility (i.e., desire to seek the truth), and wholeheartedness (i.e., willingness to make change by critically evaluating self and others).

The type of learning process different students are likely to employ is contingent on personal motivation, the amount of effort they give to solving a problem, and their individual performance goals (Pee et al., 2000; van Woerkom et al., 2002). Biggs (1987) argued that students differ in terms of when and under what conditions they would apply a deep versus a surface approach to learning. Specifically, a student engaging in a surface approach to learning sees the task as a demand to be met or as an imposition to reaching a goal; views the various aspects of the task to be discrete and independent of each other; prefers to solve the task quickly; is not concerned with attaching personal or other well engrained meanings to the task; relies on memorization; and is most concerned with basic level aspects. In contrast, students engaging in deep learning are interested in the task itself and enjoy completing the 
task; search for the inherent meaning in the task; make the task personal, attaching meaning from both a personal and a real world perspective; view the task holistically and try to integrate the individual components of the decision scenario; and try to apply theories to the task and in turn create testable hypotheses.

Related to business education, Cole et al. (2004) investigated "psychological hardiness" and its relation to students' motivation to learn (commitment), their ability to learn (control), and their willingness to change (challenge). Of particular relevance to reflective learning is the challenge construct, described by Kobasa and Pucetti (1983) as a "belief that change rather than stability is normal in life and that the anticipation of changes are interesting incentives to growth rather than threats to security" (p.169). Cole et al. conclude that "hardy persons experience activities as interesting and enjoyable, as being a matter of personal choice, and as important stimuli for learning. In ambiguous situations, hardiness equips individuals to draw upon a personal sense of commitment and control to find meaning in their tasks as well as exercise decision-making and goal-setting techniques" (p. 96).

Adapting Mezirow's (1991) multi-tiered levels of reflective and non-reflection learning, Kember et al. (2000) posited four different "hierarchical" levels of reflection: habitual action/learning, understanding, reflection, and critical reflection. Although they did not link reflection to learning outcomes, they did develop and test an instrument to determine whether students differed in their level of reflection. Their primary research hypothesis was supported in that students did differ across the four hierarchical learning dimensions. Figure 1 presents our visualization of where each of Kember et al.'s four dimensions fall along the nonreflection/surface learning $\leftrightarrow$ reflection/deep learning hierarchy and how we define each dimension. We have thus attempted to integrate the various levels of reflection with surface and deep approaches to learning, following Leung and Kember (2003) who have encouraged the use of the two interpretive frameworks in concert. Importantly, although our dimensions 
in Figure 1 occupy different scale positions on the lower-higher level learning hierarchy, as a continuum, each dimension has a certain amount of gray area as it transitions to the next higher learning dimension. ${ }^{1}$

\section{Figure 1 goes about here}

\section{Habitual Action/Habitual Learning}

Habitual action refers to "that which has been learnt before and through frequent use becomes an activity that is performed automatically or with little conscious thought" (Kember et al., 2000, p.383). Habitual actions are those that have been learned through repetition, in which a particular problem has been encountered a number of times and has been resolved in a consistent and routine fashion. Habitual action, which is consistent with a surface approach to learning, occupies the lowest level of the reflection hierarchy and involves minimal thought and engagement (Biggs et al., 2001; Leung \& Kember, 2003). According to Entwhistle and Ramsden (1983), surface learning is an attitudinal state of "unreflectiveness" through which specific tasks are processed as unrelated activities and where memorization is the most common method for learning. Schon (1983) referred to these types of decision environment and problem resolution scenarios as "knowing-inaction;" that which has become almost unconscious routine. Consistent with Mezirow's (1991) view that habitual actions involve non-reflective learning, Cope (2003) suggests that the incremental accumulation of routinized, habitual events stagnates the learning process and that which can be learned.

From a management education perspective, as a lower level learning perspective, we contend that habitual action/learning is characteristic of students who memorize rather than reflect, prefer tests over strategic learning exercises, focus only on what is required rather 
than exploring additional learning materials, and who focus more on the grade than what is learned.

H1: Habitual Action/Learning is negatively related to alumni's perceived quality of the learning experience.

\section{Understanding}

Understanding is situated at the second level in the reflection hierarchy and focuses for the most part on comprehension without relation to one's personal experience or other learning situations (Kember et al., 2000). Kember et al.'s operationalization of 'understanding' draws on Bloom's knowledge taxonomy (1979), in which understanding is equated to comprehension in that students learn without relating to other situations and/or to personal experiences. Leung and Kember (2003) contend that much of the "book learning" activities that students utilize when studying is characteristic of the understanding construct. As with habitual action, the understanding stage of the reflection hierarchy is also consistent with non-reflective thinking in that comprehension is valued over mental integration and personal assimilation but does however represent a deeper form of learning. Mezirow (1991) termed this type of learning as "thoughtful action" and noted that although understanding requires more active engagement in learning than habitual action, most of what is learned stays within the boundaries of pre-existing perspectives. In this way, a student utilizing a thoughtful action learning rule would access existing knowledge without appraising that knowledge and would process the information within pre-existing schemas.

Within a marketing education context, habitual action/learning may be seen as more process-oriented versus understanding, which is more content driven. Understanding may be seen to relate to the extent to which content required conscious thought of the student. However, as understanding is not seen to involve personal assimilation, thus representing a lower level of learning, we hypothesize that a greater focus on understanding relative to reflective learning will negatively impact perceptions of the learning experience. 
H2: Understanding is negatively related to alumni's perceived quality of the learning experience.

\section{Reflection}

Habitual action and understanding are viewed as being positioned nearer to the surface learning portion of the non-reflection $\leftrightarrow$ reflection hierarchy. The third and final hierarchical levels of the reflection process, reflection and critical/intensive reflection, are both associated more closely with deeper and more thoughtful learner and learning traits (Dewey, 1933; Mezirow, 1991). The primary difference between reflection and critical/intensive reflection is that the last stage involves a change in personal beliefs and assumptions. In defining reflection, Kember et al. (2000) draw on Mezirow (1991) who expounded that

"Reflection involves the critique of assumptions about the content or process of problem solving....The critique of premises or presuppositions pertains to problem posing as distinct from problem solving. Problem posing involves making a taken-for-granted situation problematic, raising questions regarding its validity.” (p. 105).

Mezirow further outlined two types of reflection distinct from critical reflection: content reflection, which are "Reflections on what we perceive, think, feel or act upon" (p. 107), and process reflection, "Examinations of how one performs the functions of perceiving, thinking, feeling, or acting and an assessment of the efficacy of performing them" (pgs. 107-108). Kember et al. (2000) subsequently collapsed these two types of reflection into s single dimension. Central to reflection is thus a questioning of experiences and in turn a search for alternatives and identification of areas for improvement (Pee et al., 2001). A focus on alternative ways of seeing and doing is seen as especially important in the case of the management student since exploring different perspectives will assist managers in handling complexity, uncertainty and uniqueness which are seen to characterise today's managerial world (Dehler et al., 2001). A more active form of learning is thus suggested and indeed Atkins and Murphy (1993) argue that reflection involves consideration of the wider 
implications of learning. Reflection is seen to be closely associated with a deep approach to learning where formal learning is integrated with personal knowledge and the formation of relationships between parts of knowledge and search for meaning (Entwhistle and Ramsden, 1983). Leung and Kember (2003) further suggest that deep learning is a prerequisite to reflection.

Marketing courses which encourage reflective learning may be seen to assist students in appraising their experiences and in turn identifying new and alternative solutions to problems, improving their past actions and thinking about the wider implications of their experiences. For example, case-studies or experiential exercises would be better received than lectures and exams. As reflective learning is seen to represent a form of higher level learning, we hypothesize that alumni will evaluate their learning experience more highly where reflective learning is invoked.

H3: Reflection is positively related to alumni's perceived quality of the learning experience.

\section{Critical/Intensive Reflection}

Critical reflection is at the pinnacle of the non-reflection $\leftrightarrow$ reflection hierarchy. Critical reflection represents a more intense form of reflection and involves a transformation of meaning frameworks. Drawing on Mezirow (1991), Kember et al. (2000) suggest that this form of reflection "involves us becoming aware of why we perceive, think, feel or act as we do" (p110). Kember et al. further propose that integral to such reflection is a perspective transformation where an individual critically reviews his or her internal prepositions, cumulating in changing one's assumptions and beliefs of self. Along these same lines, Boyd and Fales (1983) point out that higher level reflection and subsequent change orientation "is the process of internally examining and exploring an issue of concern, triggered by an experience, which creates and clarifies meaning in terms of self, and which results in a changed conceptual perspective" (p. 1000). Kember et al. (1999) contend that critical 
reflection and resulting internal transformations are difficult tasks in that conventional wisdom and ingrained assumptions become so deeply embedded that we may not even be aware that they are assumptions or that they actually exist.

Within the literature there would appear to be some debate surrounding the description of critical reflection in relation to business education. There is disagreement between scholars as to whether critical reflection is really 'critical' in the sense intended by Critical Theorists. Reynolds (1998) contends that critical reflection "involves analysis of power and control and an examination of the "taken for granteds" within which the task or problem is situated" (p.189) and is therefore associated with Critical Theory which seeks to challenge power relations in the pursuit of emancipatory and political ideals (Willmott, 1997). Reynolds argues that Mezirow's concept of critical reflection is not critical in this sense as it presents an explanation of personal, psychological change rather than social change. Therefore the conceptualisation of critical reflection used here cannot be seen to be consistent with Critical Theory since our focus is on the individual. However, we would argue that the self analysis and self questioning associated with reflection and the perspective self transformation in critical reflection as used here may offer the potential for social change and the development of "fundamentally better organizations, better societies and a better world by freeing managers from socially embedded assumptions" (Kayes, 2002, p138). Indeed, Cope (2003) highlighted that critical self reflection can stimulate both challenges to personal assumptions and a deeper understanding of one's business. We therefore propose that qualitative differences in levels of reflection exist and following Cope (2003) we suggest that critical reflection within our hierarchy may be more helpfully termed 'intensive reflection' to describe a deeply challenging form of reflection.

Ultimately, marketing educators stimulating intensive reflection will have accomplished the highest of all learning goals by motivating students to rethink assumptions about 
themselves and about business, and in turn, to change how they think of the world and their actions in response to this epiphany.

H4: Intensive Reflection is positively related to alumni's perceived quality of the learning experience.

\section{Conditions for Reflection}

Reflection and intensive reflection are high-order learning and change processes that are often difficult to reach (Mezirow, 1998). Moreover, both types of reflection occur in varying degrees across individuals and in different types of learning environments, and as such, a better understanding of the conditions for sparking reflective processes is a key to academic success, and ultimately, as a means of enhancing the educational experience (Hay et al., 2004a). Although underdeveloped, a review of the emerging literature suggests that two key conditions within the academic learning environment may foster reflective thinking: instructor-to-student interactions and student-to-student interactions.

\section{Instructor-to-Student Interactions}

For higher-order reflections to occur the learning environment must allow for individuals to express doubt, to explore uncertainties, and to become aware of internal and external contradictions (Boud et al., 1985). The role of the educational instructor is thus paramount to eliciting reflective learning. Importantly, the instructor must create a learning environment in which open discussion is facilitated, allowing individuals to express doubt in what is being learned, and that affords the opportunity to raise points of disagreement (Thorpe, 2001). Because reflective thinking is not necessarily an innate trait, the instructor must design the course in such a way as to build students' metacognitive awareness of their personal thought processes, that hone students' basic skills, and provides dialogs with students that are supportive and trusting (Braun, 2004; Brown \& Posner, 2001). In many ways, the instructor is a coach who leads students down the path to reflection-in-action (Schon, 1987). This importance is magnified in that many students are "reflection novices," and as such, need 
considerable guidance to move from lower to higher forms of reflective thinking (Bailey et al., 1997). Conceptually, for reflective learning to occur students should view the lecturer as a "mentor" who promotes learning in a non-threatening learning environment, by encouraging questions, and by highlighting connections among and between concepts (Bailey et al., 1997, Fisher \& Somerton, 2000, Marton \& Saljo, 1984). Clearly, the instructor is one of the most critical components of "transformational" learning and internal change (Mintzberg \& Gosling, 2004; Hay et al., 2004a; Taylor, 2000). As H5 states below, positive instructor-to-student interactions enhance the learning experience, negative interactions impair the learning experience.

H5: Instructor-to-Student interactions are directly related to alumni's perceived quality of the learning experience.

\section{Student-to-Student Interactions}

Without question, instructor-to-student interactions are critical for introducing, developing, and nurturing higher order reflective learning. However, student-to-student interactions must also play an important role in any learning process (Peltier et al., 2003; Hay et al., 2004b). Dempsey et al. (2001) contend that the sharing of thoughts and feelings with others is a fundamental requisite to reflection. In their view, transformational change is in part a function of the dialogue that takes place between students that give support to and motivates the learner to move beyond intellectual grasping of ideas to find personal meaning, and thus, to progress from understanding to reflection. Similarly, Gray (2001) argues that student-to-student interactions facilitate the application of learning to existing knowledge by introducing real world examples of the learning topic. Of interest, these interactions are no longer exclusively within the classroom, they can also occur in the electronic learning space (Hay et al., 2004b; Peltier et al., 2003). In combination, student-to-student interactions will assist the transition to a higher-order learning process and reflection-oriented transformations through vision sharing (van Woerkom, 2002), co-production of outcomes (Biggs et al., 2001), 
analyzing and comparing one's responses to others (Thorpe, 2001), and enhancing team leadership skills (Brown \& Posner, 2001). Ultimately, to achieve reflection within both an academic and an organization learning environment, learning participants need to share reflections and experiences, support and encourage, disseminate ideas and feelings outward, and assimilate the views of others (Hodgkinson \& Brown, 2003). As H6 identifies below, positive student-to-student interactions enhance the learning experience, negative interactions impair the learning experience.

H6: Student-to-Student interactions are directly related to alumni's perceived quality of the learning experience.

\section{Model Development}

Our model, which is shown in Figure 2 incorporates three components: (1) the four stages along the non-reflection $\leftrightarrow$ reflection hierarchy (habitual action, understanding, reflection, and intensive reflection), (2) two conditions within an educational setting for creating higher-order reflection (instructor-to-student and student-to-student interactions), and (3) outcome measurements pertaining to the value of the learning experience. From our review of the scant literature in this area discussed above, we hypothesize that except for Habitual Action and Understanding, all of the dimensions will be positively related to perceived quality of the learning experience.

Figure 2 goes about here

\section{METHODOLOGY}

\section{Data Collection and Sample}

The study was conducted at a Midwestern university with a large college of business and economics. In total, 323 individuals who had received their MBA in the preceding three-year period were mailed the questionnaire. MBA students were utilized because the college was undertaking an assessment of its graduate business program. A postcard promoting the survey was mailed prior to distribution of the actual questionnaire. All graduates received a two 
dollar participation incentive and anonymity was assured. A total of 220 questionnaires were returned after two mailings, for a response rate of $68.1 \%$.

\section{Questionnaire Development}

A detailed and extensive questionnaire was developed to assess perceptions regarding all four stages in the non-reflection $\leftrightarrow$ reflection hierarchy (habitual action, understanding, reflection, and intensive reflection) and the two educational setting variables (instructor-tostudent and student-to-student interactions). Given the suggested importance of reflective learning, it was surprising that few measures actually exist. Indeed, we only identified four instruments designed to assess reflection (Boenink et al., 2004; Kember et al., 2000; Sobral 2000; van Woerkom et al., 2002). Further none of these were developed within a management education context. Moreover, although there are a wide range of topics that could be viewed as important to reflective learning, the literature is scant in terms of integrating these topical areas.

When developing our questionnaire we did an extensive review of the reflection literature identified above to identify the possible domain of useful questions. We then integrated and refined statements from this literature to create our instrument. In developing the questionnaire the work of Kember et al. (2000) was especially helpful. As described above, Kember et al.'s scale includes four levels: habitual action, understanding, reflection and critical reflection which are based upon Mezirow's model of reflection. However, there was an issue with respect to the reliability of the individual scales with three of the four scales having alpha-coefficients below Nunally and Bernstein's (1993) accepted level of 0.70. Therefore, an attempt was made to improve the clarity/understanding of certain items and in some cases to relate items to a management education context. Additional items were also added to examine aspects of reflection and intensive reflection such as integration of learning with existing knowledge (Fisher \& Somerton 2000) and consideration of the wider 
implications of learning (Atkins \& Murphy 1993). Given the suggested relationship between approaches to learning and levels of reflective learning, items assessing surface and deep approaches to learning were included from Biggs et al. (2001). The literature also suggested the importance of conditions for reflection; accordingly items were developed to assess both the role of the fellow students (Braun, 2004; Brown \& Posner, 2001; Dempsey et al., 2001; Gray 2001; Hodgkinson \& Brown, 2003; Peltier et al., 2003) and the role of the professor (Bailey, et al., 1997, Fisher \& Somerton, 2000; Liimatainen et al., 2001; Thorpe 2001) in fostering reflection. Upon completion of this review we developed 56 questions across the six dimensions outlined in our model. The questionnaire also contained six global dependent measures designed to describe the value of students' overall learning experience. These included: I learned a lot in the MBA Program, I enjoyed the MBA Program, I would recommend the MBA Program to others, The MBA Program has benefited my career, The MBA Program has benefited my life generally, and Overall, I am satisfied with the MBA Program. A factor analysis revealed that all six of these questions loaded on one global learning assessment measurement. We thus collapsed all six items into one summed dimension. All items were measured via a 5-point Likert type scale that ranged from strongly agree to strongly disagree.

\section{FINDINGS}

\section{Assessing the Underlying Dimensionality and Measure Reliability}

As noted, one of our major objectives was to utilize a reflection scale that tapped into the non-reflection $\leftrightarrow$ reflection hierarchy (habitual action, understanding, reflection, and intensive reflection) and that addressed conditions for reflection (instructor-to-student and student-to-student interactions). In doing so we first factor analyzed the 56 questions concerning various facets of the MBA program. First, a principle components analysis employing varimax rotation was conducted to identify the major commonalities in the data. 
Next, the individual questions associated with each measure were evaluated using an item-tototal correlation analysis. In that previous reflection instruments were constrained by having relatively low reliability scores, no priority was given to maintaining any item from previous reflection questionnaires. Given the goal was to create highly reliable dimensions, items with low item-to-total correlations and that would raise the coefficient alpha score if removed were eliminated. The coefficient alphas for final measures were then calculated and ranged from .74 to .87 , indicating that the measures were reliable. The specific items making up each of the measures and the coefficient alphas are shown in Table 1. As predicted, all six dimensions were present in the data and support the framework of the model.

\section{Table 1 goes about here}

\section{Model Validity and Explaining Outcome Assessment}

Once dimensionality and measure reliability were confirmed, we statistically assessed the impact of each of the dimensions on MBA graduates' perceptions of the quality of the program and how it has benefited them upon entering the workforce. As we show in Table 2 and Table 3, all six of our hypotheses were supported. Using regression we first tested the relationship each of the four non-reflection $\leftrightarrow$ reflection dimensions had on perceived learning outcomes. We were particularly interested in the direction of the relationship and the relative importance each had in explaining the global outcome variable. Specifically, the factor scores for habitual action, understanding, reflection, and intensive reflection were used as the independent variables; the summed global measure was the dependent variable. The findings can be found in Table 2 .

\section{Table 2 goes about here}

A number of meaningful conclusions can be drawn from the regression findings in table 2. First, as expected, all four non-reflection $\leftrightarrow$ reflection dimensions significantly impacted the outcome variable $(\mathrm{F}=36.5$, model sig at $\mathrm{p}<.001, \mathrm{r}$-square $=.43)$. Second, although not 
well documented in the literature, our expectation was that habitual action and understanding would be negatively correlated with outcomes and that reflection, and intensive reflection would have a positive impact on outcome assessment. An examination of the standard coefficients in Table 2 provides empirical support for our directional hypotheses. Lastly, and importantly, the standardized beta coefficients show support for our premise that each stage of the non-reflection $\leftrightarrow$ reflection hierarchy becomes increasingly important in explaining perceived learning outcomes. Specifically, and in order, intensive reflection $(\operatorname{Std} \beta=3.65, \mathrm{t}$ $=7.0, \mathrm{p}<.001)$ had the highest standardized betas, followed by reflection $(\operatorname{Std} \beta=3.59, \mathrm{t}=$ $6.9, \mathrm{p}<.001)$, understanding ( $\operatorname{Std} \beta=-.351, \mathrm{t}=-6.7, \mathrm{p}<.001)$, and habitual action (Std $\beta=-$ $211, \mathrm{t}$ value $=-4.1, \mathrm{p}<.01)$. We believe this to be the first empirical test of the reflective learning hierarchy in predicting program outcomes.

Table 3 contains the findings when learning conditions related to perceptions of studentto-student and instructor-to-student interactions are included in the model $(\mathrm{F}=47.2$, model sig at $\mathrm{p}<.001, \mathrm{r}$-square $=.58$ ). As can be seen, instructor-to-student and student-to-student interactions were found to be significant and positive predictors of performance outcomes. Of significance, the relative importance of intensive reflection $(\operatorname{Std} \beta=.364, \mathrm{t}=8.1, \mathrm{p}<$ $.001)$, reflection $(\operatorname{Std} \beta=.358, \mathrm{t}=7.9, \mathrm{p}<.001)$, and understanding $(\operatorname{Std} \beta=-.351, \mathrm{t}=-7.8, \mathrm{p}$ $<.001$ was preserved. Student-to-student interactions $(\operatorname{Std} \beta=.283, \mathrm{t}=6.3, \mathrm{p}<.001)$ and instructor-to-student interactions $(\operatorname{Std} \beta=.259, \mathrm{t}=5.7, \mathrm{p}<.001)$ had a greater impact than did habitual action $(\operatorname{Std} \beta=-.212, \mathrm{t}=-4.7, \mathrm{p}<.001)$.

\section{Table 3 goes about here}

\section{DISCUSSION}

The paper has reported the results from a study designed to measure reflective learning in graduate business education. We address both the limited attention given to reflective learning within the marketing and business education literature and the scarce attention given 
to measurement of reflective learning in general. Our work integrates theoretical understandings of reflective learning from diverse subject areas to offer an instrument which assesses both levels of reflective learning and conditions for reflection. Significantly, we also demonstrate the importance of reflective learning in predicting graduates' perceptions of program quality and career enhancement.

Our review of the reflective learning literature identified six dimensions associated with reflection. The resulting factor analysis confirmed that the six dimensions were separate and important factors associated with reflective learning as perceived by graduate alumni. Four of these dimensions related to identified levels of reflective learning: habitual learning; understanding; reflection and intensive reflection. This provides further empirical support for Kember et al.'s (2000) and Mezirow's (1991) conceptualization of levels of reflective learning. Importantly, there is clear evidence here of two distinct forms of reflection: reflection and a more intensive reflection which involves changes to underlying assumptions about the self and business. This is significant as there is some debate within the literature as to the nature of the highest level of reflection within Mezirow's and Kember's frameworks (Reynolds, 1998). It would seem that although the most intensive reflection identified here may not go as far as the emancipatory ideals of Critical Theory, there is evidence of a type of reflection which involves a profound questioning and challenging of deeply held beliefs and assumptions which may in turn provide a catalyst for wider social reflection (Reynolds and Vince, 2004).

The findings here would seem to support the dualistic dichotomies found within the wider learning literature which suggest two general forms of learning: lower and higher level learning (Cope, 2003). Both habitual action and understanding may be seen to represent lower levels of learning and correlate negatively with program outcomes. Reflection and 
intensive reflection are seen to represent higher levels of learning and correlate positively with program outcomes.

Two of the dimensions identified by the factor analysis related to conditions for reflection, namely instructor-to-student interactions and student-to-student interactions. This accentuates the importance of interaction generally in fostering enhanced learning experiences and provides evidence which supports the espoused role of social exchanges to student learning (e.g. Dempsey et al., 2001; Hay et al., 2004b; Hodgkinson \& Brown, 2003; Peltier et al., 2003; Thorpe, 2001). Drawing on the items contained in the instructor-tostudent interaction dimension, the instructor in encouraging an improved learning experience may usefully encourage student questions and comments, allow doubt and disagreement within learning and create an atmosphere that allows the student to be open about their views. It is important to create a learning environment which promotes divergence and complexity of thought as is consistent with the arguments of Dehler et al. (2001) who propose the value of promotion of "complicated understanding" in business education whereby the student is encouraged to increase the variety of ways in which events can be understood. Further, it would seem that fellow students play an important role in stimulating divergent thinking by bringing to the classroom their range of ideas and ways of solving problems. Taken together this may suggest a change in the relationship between classroom participants is necessary for enhanced learning where both students and instructors play important roles, with neither taking center stage. Accordingly, the notion of a de-centered classroom where both student and instructor jointly construct knowledge has merit here (Dehler et al., 2001; Watson, 2001).

Importantly, the study also offers a reliable measure for reflective learning and thus makes a contribution to the existing field as the paucity of instruments which measure reflective learning has been observed. Of note, we have highlighted that in the case of marketing education, there have been calls from the AACSB (2004) for increased outcome 
measurements and assurance of learning reporting and thus the measures can be seen to, in part, respond to this demand. Given the importance of reflection to managerial practice (Schon 1983, 1987), it is hoped that programs which demonstrate the development of reflective learning in students can provide some form of assurance of their contribution to learning.

In the context of the wider reflective learning field, we have added to the growing consideration of ways to operationalize the construct (Kember et al., 2000; van Woerkom et al., 2002). Our scale draws on the work of Kember et al. (2000), providing further evidence of the usefulness of the four levels of reflective learning identified by these authors. We have expanded this scale to include additional items designed to tap into these four levels and items which assess approaches to learning following Leung and Kember (2003). The result of this development has been four scales which demonstrate increased reliability. In addition, the scale developed also includes items which assess conditions for reflective learning which have not previously been operationalized. Of importance, the results also show that the "continuum" nature of the reflection hierarchy makes it difficult to make mutually exclusive and/or completely delineated hierarchal dimensions along the continuum. This is evident by the fact that even though the factor loadings showed that habitual and understanding dimensions were separate dimensions, like any continuum, there is some "grey areas" at their intersection.

Our regression analysis which assessed each of the six dimensions on MBA graduates' perceptions of program quality and career enhancement reveals a number of important findings. All six of the dimensions were found to significantly impact upon the outcome variable. This provides evidence of the validity of the measures and indicates that each factor affects the perception of program quality and career enhancement in different ways. Of particular interest, is the negative relationship found between habitual learning and 
understanding and perceived program outcomes. This explicitly suggests that lower levels of learning are associated with diminished student ratings and thus highlights a concern for programs which are seen to rely on routine and non-challenging learning experiences. The analysis also established the relative importance of each factor in explaining perceived program outcomes. Consistent with our non-reflection-reflection hierarchy, each level becomes of increasing importance in explaining perceived program outcomes. Accordingly, intensive reflection is most important in accounting for variance in program outcomes, followed by reflection, understanding and habitual learning. This is important for a number of reasons. First, we believe this to be the first empirical test of the reflective learning hierarchy in predicting program outcomes. Second, the finding that intensive reflection and reflection are the two most important factors in explaining program outcomes empirically demonstrates that reflective learning is fundamental to an enhanced student learning experience. Moreover, as our outcome measure includes items assessing overall benefit to the individual's career, there is an implication that reflective learning is also positively related to the workplace. The regression analyses also revealed that our identified conditions for reflection, instructor to student interaction and student to student interaction were also significant in explaining program outcomes; however these were less important than understanding, reflection and intensive reflection. It is encouraging that the students' learning experience is of greater significance in explaining program outcomes since it is sometimes bemoaned that factors such as the instructor play an overriding part in course evaluation. In practice, marketing faculty could re-design their curriculum and class activities to match students' level of critical and reflective thinking so as to enhance their evaluative abilities (Chan et al., 2002).

The contribution of the role of the instructor and fellow students is still of importance and suggestions have been made above as to how classroom interactions can strengthen learning experiences. 


\section{LIMITATIONS AND FUTURE RESEARCH}

The work presented here is subject to a number of limitations. First, the study is based on one MBA program at one university and thus questions regarding generalizability are naturally raised. Second, as we have already noted our study represents an individual perspective of reflective learning and thus future work may seek to incorporate a social perspective consistent with Critical Theory (Reynolds, 1998). Third, our work only considers two important conditions for reflective learning, student-to-student interactions and instructor-to-student interactions, there are obviously further conditions worthy of consideration such as assessment and course design (Thorpe, 2001) for instance.

Our study also raises a number of suggestions for areas of future research. Further work may seek to examine the interrelationships between important dimensions of reflective learning, for example, does reflection influence intensive reflection? This can be investigated by the use of structural equation modeling. Our work is based upon graduates' perceptions of an overall program, there may be merit in conducting similar research at the course level to identify differences relating to specific courses, for example a comparison of courses such as quantitative analysis and organizational theory. Further, there may also be benefit in conducting a longitudinal study which is able to follow the development of the student's ability to reflect throughout the program. It may also be interesting to assess international differences in reflective learning. For example, a comparison between the US and the UK may be of interest since scholars have recognized the increased consideration of Critical Management Education in the UK relative to the US (Grey, 2004) and we have noted the potential importance of reflection to this. Lastly, future research should also address whether reflective thinking differs by business discipline and for graduate versus undergraduate students. 


\section{CONCLUSION}

In conclusion, our work is seen to progress the consideration of reflective learning within the context of business education and provides a reliable and valid instrument for management educators to assess reflective learning in their students. Further empirical investigation of the reflection construct will significantly enhance conceptual developments within the field. This is seen to be of vital importance to marketing education given the increasing value placed on helping current and future managers to become more critically reflective. 


\section{Endnotes}

${ }^{1}$ As will be seen through the orthogonal factor analysis, the learning dimensions are distinct and uncorrelated. However, adjacent learning dimensions had factor loadings in the .2 to .25 range; significant but not meeting the standards for inclusion in a dimension. 


\section{References}

AACSB International, 2004. Assurance of learning requirements. http://www.aacsb.edu/resource centers/assessment/standards.asp

Argyris, C. 2002. Double-loop learning, teaching, and research. Academy of Management Learning \& Education, 1(2): 206-218.

Argyris, C. \& Schon, D.A. 1996. Organizational learning II: Theory, method and practice. Reading, MA: Addison-Wesley Publishing.

Atkins, S., \& Murphy, K. 1993. Reflection: A review of the literature. Journal of Advanced Nursing, 18: $1188-1192$.

Bailey, J.R, Saparito, P., Kressel, K., Christensen, E., \& Hooijberg, R. 1997. A model for reflective pedagogy. Journal of Management Education, 21(2): 155-167.

Bennis, W. \& Nanus, B. 1997. Leaders: The strategies for taking charge. New York, NY: Harper and Row.

Biggs, J., Kember, D., \& Leung, D.Y.P. 2001. The revised two-factor study process questionnaire: RSPQ-2F. British Journal of Educational Psychology, 71: 1333-1349.

Biggs, J. 1987. Student approaches to learning and studying. Melbourne: Australian Council for Educational Research.

Bloom, B.S. 1979. Taxonomy of educational objectives, book 1: Cognitive domain. London: Longman.

Boenink, A.D., Oderwald, A.K., De Jonge, P., Van Tilburgh, \& W., Smal, J.A. 2004. Assessing student reflection in medical practice. The development of an observer rated instrument: Reliability, validity and initial experiences. Medical Education, 38: 368-377.

Boud D., Keogh R., \& Walker, D. 1996. Promoting reflection in learning: A model. In Knowing, learning and instruction edited by L. Resnick. London: Rutledge.

Boud, D., Keogh, R., \& Walker, D. 1985. Reflection: turning experience into learning. London: Kegan Page.

Bourner, T. 2003. Assessing reflective learning. Education \& Training, 45(4/5): 267-273.

Boyd, E.M., \& Fales, A.W. 1983. Reflective learning: Key to learning from experience. Journal of Humanistic Psychology, 23(2): 99-117.

Braun, N.M. 2004. Critical thinking in the business curriculum. Journal of Education for Business, March/April: 232-236.

Brown, L., \& Posner, B.Z. 2001. Exploring the relationships between learning and leadership. Leadership and Organisation Development Journal, 22(6): 274-280.

Catterall, M., Maclaran, P., and Stevens, L. 2002. Critical reflection in the marketing curriculum. Journal of Marketing Education, 24 (December): 184-192.

Chan, C. C., Tsui, M. S., Chan, Mandy Y. C., and Hong, Joe H 2002. Applying the structure of the observed learning outcomes (SOLO) taxonomy on student's learning outcomes: An empirical study. Assessment \& Evaluation in Higher Education, 27 (6): 511-527.

Cole, M.S., Feild, H.S., \& Harris, S.G. 2004. Student learning motivation and psychological hardiness: Interactive effects on students' reactions to a management class. Academy of Management Learning \& Education, 3(1): 64-85.

Cope, J. 2003. Entrepreneurial learning and critical reflection. Management Learning, 34(4): 429-450.

Corley A., \& Eades, E. 2004. Becoming critically reflective practitioners: Academics' and students' reflections on the issues involved. Human Resource Development International, 7(1): 137-144.

Dehler, G.E., Welsh, A., \& Lewis, M.W. 2001. Critical pedagogy in the 'new paradigm.' Management Learning, 32(4): 493-511.

Dempsey, M., Halton, C., \& Murphy, M. 2001. Reflective learning in social work education: Scaffolding the process. Social Work Education, 20(6): 631-641.

Densten, I.L., \& Gray, J. 2001. Leadership development and reflection: What is the connection?. The International Journal of Educational Management, 15(3): 119-124.

Dewey, J. 1933. How we think: A restatement of the relation of reflective thinking to the education process. Boston, MA: DC Health.

Duke, C. R. 2002. Learning outcomes: comparing student perceptions of skill level and importance. Journal of Marketing Education, 24 (3): 203-217.

Enwhistle, N., \& Ramsden, P. 1983. Understanding student learning. London: Croon Helm. 
Faranda, W. T, and Clarke, I. III. 2004. Student observations of outstanding teaching: Implications for marketing educators, Journal of Marketing Education, 26 (3): 271-281.

Fisher, T., \& Somerton, J. 2000. Reflection on action: The process of helping social work students develop their theory in practice. Social Work Education, 19(4): 387-401.

Friga, P.N., Bettis, R.A., \& Sullivan, R.S. 2003. Changes in graduate management education and new business school strategies for the $21^{\text {st }}$ century. Academy of Management Learning and Education, 2(3): 233-248.

Graeff, H. 1997. Bringing reflective learning to the marketing research course: A co-operative learning project using intergroup critique. Journal of Marketing education, 19 (spring), 53-64.

Gray, D. 2001. Work based learning, action learning and the virtual paradigm. Journal of Further and Higher Education, 25(3): 315-324.

Grey, C. (2004). Reinventing business schools: The contribution of critical management education. Academy of Management Learning and Education, 3(2): 178-186.

Harrison, M., Short, C., \& Roberts, C. 2003. Reflecting on reflective learning: The case of geography, earth and environmental sciences. Journal of Geography in Higher Education, 27(2): 133-152.

Hay, A., Peltier, J.W., \& Drago, W.A. 2004a. Reflective learning and on-line management education: A comparison of traditional and on-line MBA students. Strategic Change, 13(4): 169-182

Hay, A., Hodgkinson, M., Peltier, J.W., \& Drago, W.A. 2004b. Interaction and virtual learning. Strategic Change, 13(4): 193-204.

Hodgkinson, M., \& Brown, G. 2003. Enhancing the quality of education: A case study and some emerging principles. Higher Education, 45: 337-352.

Kayes, D.C. 2002. Experimental learning and its critics: Preserving the role of experience in management learning and education. Academy of Management Learning and Education, 1(2): 137-149.

Kember, D., Biggs, J., Leung, D. 2004. Examining the multidimensionality of approaches to learning through the development of a revised version of the learning process questionnaire. British Journal of Educational Psychology, 74 (2): 261-278.

Kember, D. and Leung D.Y.P. 2005. The influence of active learning experiences on the development of graduate capabilities. Studies in Higher Education, 30 (2): 155-160.

Kember, D., Leung D.Y.P., Jones, A., Loke, A.Y., Mckay, J., Sinclair, K., Tse, H., Webb, C., Wong, F.K.Y., Wong, M., \& Yeung, E. 2000. Development of a questionnaire to measure the level of reflective thinking. Assessment and Evaluation in Higher Education, 25(4): 382-395.

Kember, D., Jones, A., Loke, A., McKay, J., Sinclair, K., Tse, H., Webb, C., Wong, F., Wong, M. \& Yeung, E. 1999. Determining the level of reflective thinking from students' written journals using a coding scheme based on the work of Mezirow. International Journal of Lifelong Education, 18(1): 18-30.

Kobasa, S. C., \& Puccetti, M. C. 1983. Personality and social resources in stress resistance. Journal of Personality and Social Psychology, 45: 839-850.

Kolb, D.A. 1984. Experiential learning as sources of learning and development. Englewood Cliffs, NJ: Prentice Hall.

Kouzes, J.M. \& Posner, B.Z. 2002. The leadership challenge. Hoboken, NJ: Wiley.

Leung, D.Y.P., \& Kember, D. 2003. The relationship between approaches to learning and reflection upon practice. Educational Psychology, 23(1): 61- 71.

Liimatainen, L., Poskiparta, M., Karhila, P., \& Sjogren, A. 2001. The development of reflective learning in the contest of health counselling and health promotion during nurse education. Journal of Advanced Nursing, 34(5): 648-658.

Loo, R. 2002. Journaling: A learning tool for project management training and team-building. Project Management Journal, 33(4): 61-66.

Maclellan, E. 2004. How effective is the academic essay?.Studies in Higher Education, 29(1): 75-89.

Marton, F., \& Saljo, R. 1984. Approaches to learning. In The experience of learning edited by F. Marton, D. Hounsell, \& N. Entwhistle. Edinburgh: Scottish Academic Press.

Mezirow J. 1998. On critical reflection. Adult Education Quarterly, 48: 185-198.

Mezirow J. 1991. Transformative dimensions of adult learning. San Francisco, CA: Jossey Bass

Mezirow, J. 1981. A critical theory of adult learning and education. Adult Education, 32: 3-24. 
Mezirow, J. 1977. Perspective transformation. Studies in Adult Education, 9: 153-164.

Mintzberg, H., \& Gosling, J.R. 2004. The education of practicing managers. MIT Sloan Management Review, Summer: 19-22.

Mintzberg, H., \& Gosling, J.R. 2002. Reality programming for MBA's. Strategy and Business, 26(1): 28-32.

Mukherjee, A. 2004. Promoting higher order thinking in MIS/CSI students using class exercises. Journal of Information Systems Education, 15(2): 171-179.

Nunally, J., \& Bernstein, I. 1993. Psychometric Theory, $3^{\text {rd }}$ Edition. New York, NY: McGraw Hill.

Paswan, A.K and Young, J.A. 2002. Student evaluation of instructor: A nomological investigation using structural equation modelling, 24 (3): 193-202.

Pee B., Woodman T., Fry H., \& Davenport, E.S. 2000. Practice-based learning: Views in the development of a reflective learning tool. Medical Education, 34: 754-761.

Peltier, J., Drago, W., \& Schibrowsky, J. 2003 Virtual communities and the assessment of online marketing education. Journal of Marketing Education, 25(3): 260-276.

Pfeffer, J., \& Fong, C.T. 2002. The end of business schools? Less success than meets the eye. Academy of Management Learning and Education, 1(1): 78-95.

Porter, L., \& McKibbin, L.E. 1988. Management education and development: Drift or thrust in the $21^{\text {st }}$ century. New York, NY: McGraw-Hill.

Reynolds, M. \& Vince, R. 2004. Critical management education and action-based learning: Synergies and contradictions. Academy of Management Learning \& Education, 3(4): 442-457.

Reynolds, M. 1998. Reflection and critical reflection in management learning. Management Learning, 29(2): 182-200.

Richards-Wilson, S. 2002. Changing the way MBA programs do business: Lead or languish. Journal of Education for Business, May/June: 296-300.

Schon, D.A. 1983. The reflective practitioner. London: Temple Smith.

Schon, D.A. 1987. Educating the reflective practitioner. San Francisco, CA: Jossey Bass.

Smart, D.T., Kelley, C.A., and Conant, J. S. 2003. Mastering the art of teaching: Pursuing excellence in a new millennium. Journal of Marketing Education, 25 (1): 71-78.

Smith, L. W. and Van Doren, D. C. 2004. The reality-based learning method: A simple method for keeping teaching activities relevant and effective Journal of Marketing Education, 26 (1): 66-74.

Sobral, D.T. 2000. An appraisal of medical students' reflection-in-learning. Medical Education, 34(3): 182-187.

Stevens, G.E. 2000. The art of running a business school in the new millennium: A dean's perspective. Society for Advancement of Management Advanced Management Journal, 65(3): 2124.

Taylor, E. 2000. Analyzing research on transformational learning, in Mezirow, J. and Associates, Learning as transformation: Critical perspectives on a theory. San Francisco, CA: Jossey Bass.

Thorpe, M. 2001. Reflective learning and distance learning-made to mix by design and assessment. Information Services and Use, 20: 145-158.

Van Velzen, J.H. 2004. Assessing students' self-reflective thinking in the classroom: The selfreflective thinking questionnaire. Psychological Reports, 95 (Dec): 1175-1186.

Van Woerkom, M. 2004. The concept of critical reflection and its implications for human resource development. Advances in Developing Human Resources, 6(2): 178-192.

Van Woerkom, M., Nijhof W.J., \& Nieuwenhuis, L.F.M. 2002. Critical reflective working behavior: A Survey. Journal of European Industrial Training, 28(8): 375-383.

Watson, T.J. 2001. Beyond managism: negotiated narratives and critical management education in practice. British Journal of Management, 12: 385-396.

Wilhelm, W. B. 2004. The relative influence of published teaching evaluations and other instructor attributes on course choice. Journal of Marketing Education, 26 (1): 17-30.

Willmott, H. 1997. Critical Management Learning. In Management learning: integrating perspectives in theory and practice edited by J. Burgoyne \& M. Reynolds. London: Sage.

Young, M. R. 2005. The motivational effects of the classroom environment in facilitating selfregulated. Journal of Marketing Education, 27 (1): 25-40. 
Young, M. R, Klemz, B. R., and Murphy, J. W. 2003. Enhancing learning outcomes: The effects of instructional technology, learning styles, instructional methods, and student behavior. Journal of Marketing Education, 25 (2): 130-142. 


\section{Biographical Information}

Professor James W Peltier is the Arno Kleimenhagen Professor of Marketing in the College of Business and Economics at the University of Wisconsin-Whitewater. He gained his PhD from the University of Wisconsin-Madison with a focus on marketing and advertising. His research interests include online education, reflective learning, database marketing, customer relationship management, advertising and health care marketing.

Dr Amanda Hay is Senior Lecturer in the Department of Human Resource Management, Nottingham Business School, Nottingham Trent University, UK. Amanda is a Chartered Psychologist and holds a $\mathrm{PhD}$ in work psychology. Her research interests include management education, reflective learning, careers and workplace trust.

Professor William Drago is Professor of Management in the College of Business and Economics at the University of Wisconsin-Whitewater. He earned his $\mathrm{PhD}$ from the University of Arkansas in Business Administration with an emphasis on strategic management. His research interests include strategic management and organization theory and more recently management of technology and online education and reflective learning. 
Table 1

Factor Model of Dimensions of Reflective Learning and Interaction

\begin{tabular}{|c|c|c|c|c|c|c|}
\hline & $\begin{array}{c}\text { Intensive } \\
\text { Reflection }\end{array}$ & Reflection & $\begin{array}{l}\text { Student } \\
\text { Interact }\end{array}$ & $\begin{array}{c}\text { Instructor } \\
\text { Interact }\end{array}$ & $\begin{array}{l}\text { Habitual } \\
\text { Learning }\end{array}$ & $\begin{array}{c}\begin{array}{c}\text { Under } \\
\text { standing }\end{array} \\
\end{array}$ \\
\hline What I learned made me rethink my assumptions about business & .687 & & & & & \\
\hline I learned many new things about myself & .665 & & & & & \\
\hline As a result of this program I have changed the way I normally do things & .658 & & & & & \\
\hline As a result of this program I have changed the way I look at myself & .656 & & & & & \\
\hline What I learned forced me to rethink how I view the world & .647 & & & & & \\
\hline I discovered faults in what I previously believed to be right & .641 & & & & & \\
\hline Course content changed many of my firmly held ideas & .639 & & & & & \\
\hline I learned more about my own learning process & .532 & & & & & \\
\hline I often re-appraised my experiences so I could learn from them & & .682 & & & & \\
\hline I often reflected on my actions to see whether I could improve them & & .650 & & & & \\
\hline I often tried to think about how I could do something better next time & & .638 & & & & \\
\hline I liked to think about my actions to find alternative ways of doing them & & .613 & & & & \\
\hline I explored my past experiences as a way of understanding new ideas & & .596 & & & & \\
\hline I spent considerable time exploring alternative solutions to problems & & .585 & & & & \\
\hline I often thought of wider implications of what I was learning & & .557 & & & & \\
\hline I often related course material to my own experiences & & .512 & & & & \\
\hline My fellow students challenged me to think & & & .700 & & & \\
\hline I enjoyed learning new ways of thinking from other students & & & .671 & & & \\
\hline I sought feedback from others about the decisions that I made & & & .664 & & & \\
\hline Other students helped me learn about solving real world problems & & & .660 & & & \\
\hline My fellow students valued my opinions & & & .638 & & & \\
\hline There was an open exchange of new ideas between students & & & .606 & & & \\
\hline Were willing to talk about things that I disagreed with & & & & .742 & & \\
\hline Encouraged student questions and comments & & & & .720 & & \\
\hline Valued my opinions & & & & .696 & & \\
\hline Allowed me to express doubt in what I was learning & & & & .695 & & \\
\hline Created an atmosphere that allowed me to be open about my views & & & & .609 & & \\
\hline Often asked questions to help me think more deeply & & & & .531 & & \\
\hline Memorizing things was often more important than understanding them & & & & & .697 & \\
\hline I usually only focused what I thought the instructor would test me on & & & & & .692 & \\
\hline I was better at taking tests than doing more strategic assignments & & & & & .665 & \\
\hline If it was not going to be evaluated, we should not have had to study it & & & & & .617 & \\
\hline My goal was to get a good grade while doing as little work as possible & & & & & .471 & \\
\hline Course content was repetitious so I often did not need to think & & & & & & .720 \\
\hline Much of what I learned I already knew & & & & & & .706 \\
\hline Much of what I learned required little or no thinking & & & & & & .697 \\
\hline The program required understanding concepts taught by the instructor & & & & & & .501 \\
\hline I had to continually think about material being taught & & & & & & .451 \\
\hline VARIANCE EXPLAINED $=56.3 \%$ & 11.8 & 10.8 & 8.8 & 8.5 & 7.4 & 7.0 \\
\hline COEFFICIENT APLHA & .87 & .85 & .80 & .80 & .75 & .75 \\
\hline
\end{tabular}


Table 2

Regression Model for Non-Reflection $\leftrightarrow$ Reflection Dimensions

\begin{tabular}{|l|c|c|c|}
\hline $\begin{array}{l}\text { Non-Reflection } \leftrightarrow \text { Reflection } \\
\text { Dimensions }\end{array}$ & $\begin{array}{l}\text { Standardized } \\
\text { Beta Coefficient }\end{array}$ & t-Value & Significance \\
\hline Intensive Reflection & .365 & 7.0 & .001 \\
\hline Reflection & .359 & 6.9 & .001 \\
\hline Understanding & -.351 & -6.7 & .001 \\
\hline Habitual Action & -.211 & -4.1 & .001 \\
\hline R-Square $=.43, \mathrm{~F}=39.45$, Model Significant at $\mathrm{p}<.001$ \\
\hline
\end{tabular}


Table 3

Full Reflection Model

\begin{tabular}{|l|c|c|c|}
\hline $\begin{array}{l}\text { Reflection } \\
\text { Dimension }\end{array}$ & $\begin{array}{l}\text { Standardized } \\
\text { Beta Coefficient }\end{array}$ & $\mathrm{t}$-Value & Significance \\
\hline Intensive Reflection & .364 & 8.1 & .001 \\
\hline Reflection & .358 & 7.9 & .001 \\
\hline Understanding & -.351 & -7.8 & .001 \\
\hline Student Interaction & .283 & 6.3 & .001 \\
\hline Instructor Interaction & .259 & 5.7 & .001 \\
\hline Habitual Action & -.212 & -4.7 & .001 \\
\hline R-Square $=.58, \mathrm{~F}=47.2$, Model Significant at $\mathrm{p}<.001$ \\
\hline
\end{tabular}


Figure 1

The Non-reflection $\leftrightarrow$ Reflection Continuum

\section{Surface learning}

\section{Habitual Action}

Minimal thought and engagement, correlated with a surface approach to learning -- specific tasks are treated as unrelated activities, memorisation is emphasised, and which embodies an attitudinal state of unreflectiveness.

\section{Understanding}

Focuses on

comprehension without relation to one's personal experience or other learning situations. Book learning as being understanding oriented in that the learner need only comprehend the read materials. Most of what is learned stays within the boundaries of pre-existing perspectives

\section{Reflection}

Learning is related to personal experience and other knowledge.

Reflection also involves challenging assumptions, seeking alternatives, identifying areas for improvement. Shows active and conscious engagement, characteristics commonly associated with a deep approach to learning
Deep Learning

\section{Intensive \\ Reflection}

Intensive reflection is at the highest level of the reflective learning hierarchy and learners become aware of why they think, perceive or act as they do. Learner might alter or even completely change firmly held beliefs and ways of thinking. Intensive reflection is thus seen as involving a change in personal beliefs. 
Figure 2

Model of Reflective Learning

\section{LEARNING CONDITIONS}

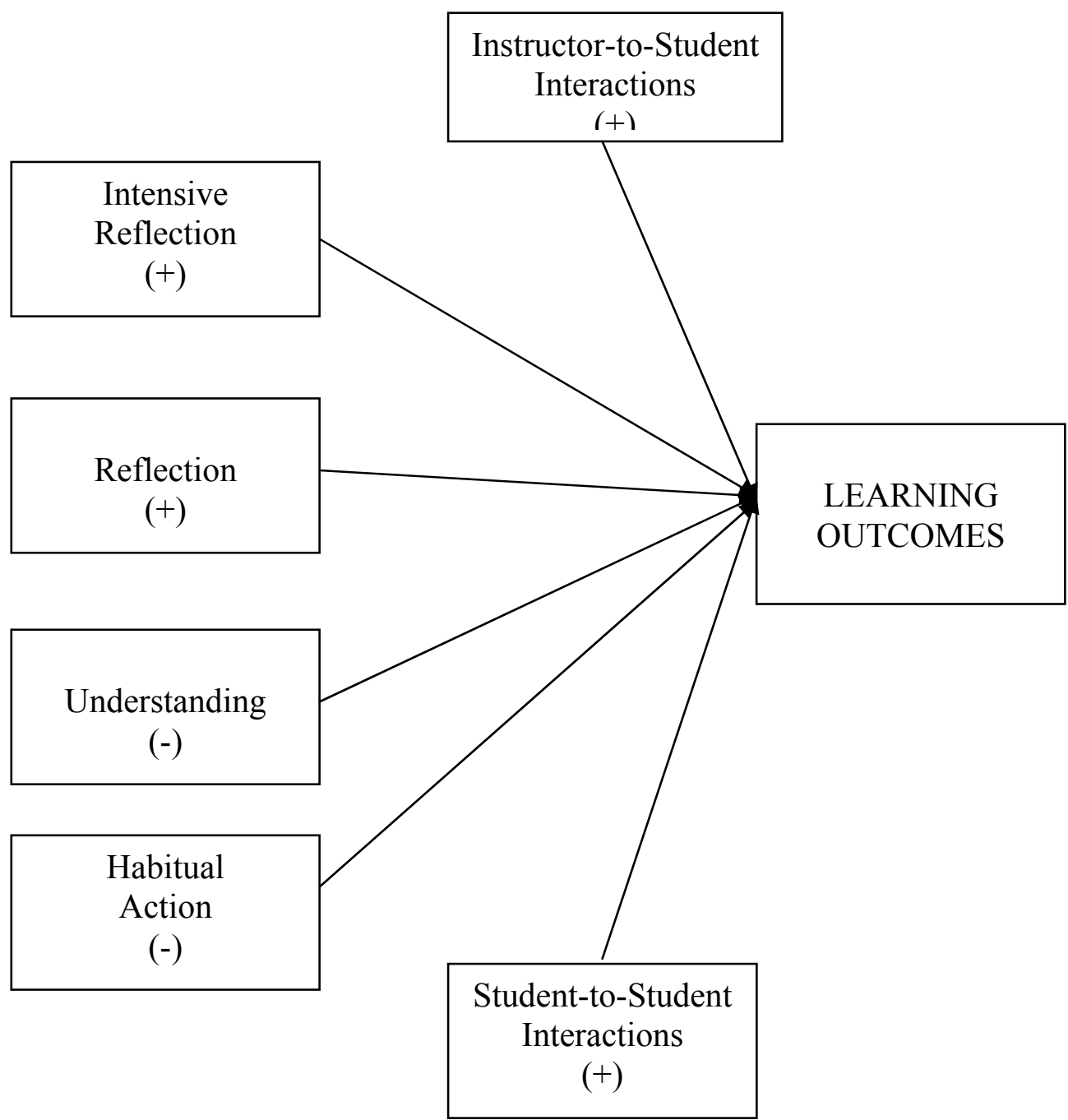

